\title{
Report of the United States of America National Committee to the XIII General Assembly of the In- ternational Scientific Radio Union, London, England, September 5 to 15, 1960.
}

\begin{abstract}
Foreword
The U.S.A. National Committee Report for the period 1957-1960 represents a departure from previous reports in scope and form. The Committee decided that a concerted effort should be made by the Commissions to review the work in their fields more critically than was done heretofore. The evaluation of progress rather than a bibliographical summary and a résumé that places the status of the field in its proper perspective were set as major objectives. The members of the Commissions responded enthusiastically to the call for contributions and the objectives have been met in a large measure. We hope that the National Committee Report will itself furnish a basis for discussions at the General Assembly and it represents a step forward in the activity of the National Committee.

The National Bureau of Standards has given inestimable aid to the preparation of the report for presentation to the General Assembly. An editorial group under Mr. Bradford Bean undertook the enormous task of uniformizing the method of referencing and of checking the references and preparing the manuscript for final printing. Time was too limited to allow for extensive editing of the manuscripts and in some cases the reports are more than coverages of the period 1957-1960. However, such deviations and expansions are not without value in a first presentation of this type.
\end{abstract}

U.S.A. National Committee 
Table of Contents

Commission 1. Radio Measurement Methods and Standards:

Review of developments

1. Frequency and time interval.

1.1. Quartz crystal standards

1.2. Atomic frequency and time standards

1.3. Frequency and time measurement and comparison $\ldots \ldots \ldots \ldots \ldots$

1.4. References _.........

2. RF and microwave power measurements

References _- 596

3. Impedance measurements and standards . . Deschamps 598

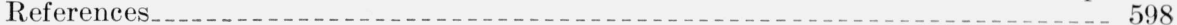

4. Development in attenuation measurements and standards__ Bruno O. Weinschel 599

4.1. Definition of attenuation._._.

4.2. Techniques for insertion loss or attenuation measurements $\ldots 599$

4.3. Self-calibrating techniques.

References _... _. 600

5. Noise measurements and standards__._. Oliver 601

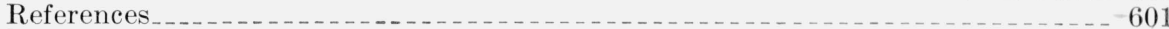

6. Field strength measurements _... Selby 603

References__._.

7. Measurements of physical quantities by radio techniques _ _ M. C. Thompson, Jr. 605

References_._.

Commission 2. Tropospheric Radio Propagation:

National Committee Report _._. 607

1. Physical characteristics of the troposphere

1.1. Synoptic scale _...

1.2. Refractive irregularities_................ 608

1.3. Absorption in the troposphere _. _ _ _ _ _ 609

2. Tropospheric propagation (theories) _.

2.1. Ground wave propagation _...

2.2. Back scattering from rough surfaces _...

2.3. Theory of propagation through a stratified atmosphere $\ldots \ldots 13$

2.4. Line-of-sight scintillation _... _. _ _ _ _ _ _ _ 613

2.5. Scatter propagation $\ldots$

a. Layers _

b. Blobs $\ldots$

3. Experimental results from investigations of tropospheric propagation

3.1. Attenuation with distance_._. _ _ _ _ _ _ _

Data sources for report and chart

3.2. Effects of rough terrain

a. Forward scattering

b. Backscattering .

3.3. Angular diversity _...

3.4. Frequency diversity

3.5. Diversity improvement _. _ _ _ _ 619

3.6. Phase stability

4. Radio meteorology _ _ 621

4.1. Climatic investigations ___ _ 621

4.2. Refractometer investigations $\ldots \ldots \ldots 21$

4.3. Refraction _._.

4.4. Radar meteorology

5. References _._. 622

Commission 3. Ionospheric Radio Propagation:

Review of U.S.A. activity, 1957-59
Structure of the upper atmosphere

2. Ionizing radiations

3. Electron densities _.

4. Satellite beacon studies.

5. Ionospheric processes

6. Ionospheric disturbances _._. 631

7. Sporadic $E$ and spread $F$

8. Studies of the lower ionosphere 631

9. Radar studies of auroral ionization 631

10. Refraction in the ionosphere

11. Ionospheric propagation studies general 632

12. Ionospheric scatter transmission

13. Radio reflection from meteor ionization 632

13.1. The reflection properties of individual trails $\ldots \ldots$

13.2. Computation and measurement of the gross propagation characteristics of

13.3. The study of ionospheric motions through the use of meteor trails as indi-

14. Ionospheric propagation research with communication systems applications

14.1. Multipath effects _ _

14.2. Fading

14.3. Arctic propagation 633

14.4. General

References 
Commission 4. Radio Noise of Terrestrial Origin:

1. Radiofrequency radiation from lightning discharges_________ A. Glen Jean 638

2. Properties of atmospheric noise at various receiving locations_William Q. Crichlow 640

3. Summary of research on whistlers and related phenomena

3.1. Stanford University

R. A. Helliwell 642

a. Methods of whistler analysis

b. IG Y-IGC synoptic whistler results

642

d. Association between aurorae and VIF hiss observed at Byrd Station, 643 Antaretica

e. Duct theory $\ldots$

f. Ray path calculations

g. Electron density of the outer ionosphere

h. Theory of VLF emissions

i. Controlled whistler - mode experiments

j. Satellite measurements _ _

k. Geocy clotron $\ldots \ldots \ldots \ldots$

3.2. Dartmouth College

a. Whistlers - East $\ldots \ldots \ldots 4$

(1) Whistlers

(2) Ionospherics $\ldots \ldots \ldots \ldots$

b. E $4^{\circ}$ (Geomagnetic) stations: successor to whistler East _ $\ldots 646$

c. Post-IGY results _

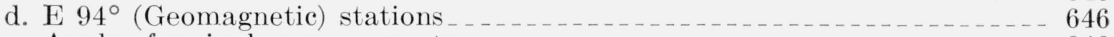

e. Angle of arrival measurements $\ldots \ldots$

f. Acknowledgment _._. 646

4. A summary of VLF and ELF propagation research_. James R. Wait 647

4.1. Introduction _._. 647

4.2. Theoretical studies

4.3. Experimental studies

4.4. Recent applications of VLF propagation _. _ _ 648

5. Hydromagnetic waves and ELF oscillations in the ionosphere _ James M. Watts 650

6. The exosphere _._. James M. Watts 651

6.1. Introduction

6.2. Theories of the exosphere

a. Magnetic storm effects _ _ _ _ _ _ _ _ 651

b. Radiation belt theory

c. Composition of the exosphere _.

6.3. Experiments in the exosphere

7. References $\ldots \ldots \ldots 52$

Commission 5. Radio Astronomy:

Review of developments

1. University of Alabama $\ldots 55$

2. Air Force Cambridge Research Center

3. U.S. Army Signal Research and Development Laboratory _

4. California Institute of Technology _ _ _ _ 656

5. Carnegie Institution of Washington $\ldots$

6. Cornell University

7. Collins Radio Company

8. University of Colorado

9. Harvard University _

10. Hayden Planetarium _._.

11. University of Illinois

12. U.S. Naval Research Laboratory

12.1. Planets:

Venus

Jupiter

Mars $\ldots$

12.2. Cosmic radio sources

12.3. Sun _............. 662

12.4. Moon $\ldots$

12.5. Atmospheric attenuation

13. The National Aeronautics and Space Administration 663

14. National Bureau of Standards, Boulder Laboratories _ _ _ _ _ _ _ _ _ _ 664

15. National Radio Astronomy Observatory

15.1. The flux density of radiation from Cas A at $1400 \mathrm{Mc} / \mathrm{s} \ldots 64$

16. Ohio State University _

17. Rensselaer Polytechnic Institute

18. Stanford University _...

19. Yale University

20. University of Michigan _._. 666

20.1. University of Michigan 85-foot radio telescope

20.2. Traveling-Wave tube receiver at $8000 \mathrm{Mc} / \mathrm{s} \ldots \ldots 6$

20.3. Maser radiometer at $8700 \mathrm{Mc} / \mathrm{s}_{\ldots} \ldots \ldots \ldots \ldots 6$

20.4. Radiometer at $1.8 \mathrm{CM}$ wavelength

20.5. Theoretical radio spectrum of Venus _ _

References_.......... 667 
Commission 6. Radio Waves and Circuits:

Subcommission 6.1. Information Theory:

Part 1. Information theory and coding

1. Foundations

2. Binary channels _ _ 671

3. Sequential decoding _._.

4. Conclusions on coding _... 672

5. Other topics _._. 672

6. References $\ldots$

Part 2. Random processes__._._. Swerling 674

References _..._._.

Part 3. Pattern recognition

Arthur Gill 676

3.1. Redundancy removal _._. _ _ _ _ _ 676

3.2. Recognition programs

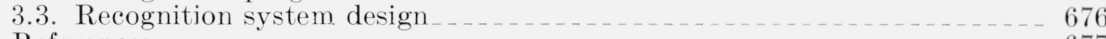

References $\ldots$

Part 4. Detection theory _ Robert Price 678

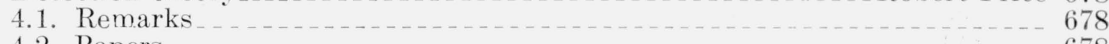

4.2. Papers _._._. 678

4.3. Bibliography:

a. Applications to radar

b. Applications to communications ___ _ _ _ 679

c. Sequential decision _. 679

d. Detection of stochasic signals in noise 679

e. Parameter estimation _____ 679

f. Loss in nonlinear devices $\ldots 679$

g. Attacks on the a priori problem _._. 680

h. Miscellaneous

(2) 680

Part 5. Prediction and filtering ___ L. A. Zadeh 681

5.1. Nonlinear filtering _._. _ _ _ _ _ _ _ 681

5.2. Filtering and radiation of nonstationary, discrete-time, and mixed processes_...

5.3. Miscellaneous contributions _._. 684

Bibliography _.. 684

Subcommission 6.2. Circuit Theory:

Circuit theory

Louis Weinberg 687

1. Introduction _ _ 6887

2. Combinatorial topology or linear graphs

2.1. Future research activity and evaluation _ 689

3. Synthesis by pole-zero techniques _.__ 692

3.1. Future research acitivity ___ 694

4. Realizability conditions and positive real matrices ___ _ 696

4.1. Future research _ _ _ 696

5. Systems with time-varying and nonlinear reactances__ 698

6. Active systems _._. 700

6.1. Active RC synthesis

6.2. Adaptive systems _._. 701

6.3. Tunnel-diode networks

6.4. Future research activity ___ 702

7. Concluding remarks _._. 703

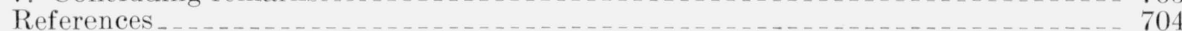

Subcommission 6.3. Antennas and Waveguides:

Part 1. Diffraction and scattering

1. High-frequency diffraction

1.1. Canonical problems

1.2. Approximate theories

Summary

2. Rayleigh scattering

3. The resonance region

4. Future activities

5. References

Part 2. On multiple scattering of waves_........ Twersky 715

1. Purpose

2. General considerations _._. 715

3. Survey

3.1. Fixed configurations of $N$ seatterers _ _ _ _ 718

3.2. Infinite planar lattices

3.3. Planar random distributions _._._._._.

a. Sparse distribution (two dimensional "rare gas") $\ldots 722$

b. General statistical distribution $\ldots$

3.4. Periodic volume distributions _._._.

3.5. Random volume distributions

References

Part 3. Antennas
1. Introduction

2. Broadband antennas 731

Bibliography 
3. Dynamic antennas _...

Bibliography _...

4. Large aperture antennas .

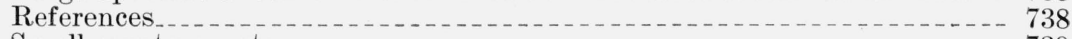

5. Small aperture antennas. 739

References............ 741

A bibliography on coherence theory

Text__._.

References .

A bibliography of automatic antenna data processing

Text

References

Surface and leaky wave antennas.

1. Surface wave antennas $\ldots \ldots$

2. Leaky wave antennas _._.

3. Assessment and predictions . . . . . . . . . .

References _.

Commission 7. Radio Electronics:
1. Parametric amplifiers__. K. Tien and H. Heffner 751

1.1. General theory and historical development

1.2. Ferromagnetic amplifier - theory and experiment_... 751

1.3. Diode amplifiers and noise figure measurements _................... 752

1.4. Electron beam parametric amplifier-space-charge wave parametric amplifier and Adler's tube

References_._.

2. Microwave properties of ferrites

2.1. Finite waveguide components, frequency doubler and mixer, and ferromagnetic amplifiers

2.2. Linewidth of single crystal yttrium-iron garnet surface imperfections and rare earth impurities _...

2.3. Instabilities and magnetostatic modes

References $\ldots \ldots \ldots$

3. Progress in solid-state masers

3.1. Cavity-type solid-state masers: experimental results _._. _... _... 758

3.2. Applications of solid-state masers

3.3. Solid-state masers: theory and analysis $\ldots \ldots \ldots 78$

3.4. Maser materials _._.

3.5. Pulsed and two-level masers

3.6. Traveling-wave masers

3.7. Noise in masers

3.8. Infrared and optical masers _._.

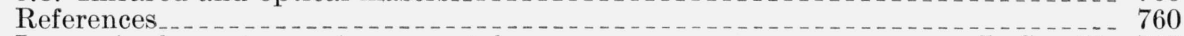

4. Low-noise beam-type microwave tubes

4.1. Progress during the past three years _...

a. Design of solid-beam, low-noise guns

b. Theory of noise on beams and low-noise amplifications

c. Hollow beam low-noise guns

d. Theory of noise in multivelocity electron beams

e. Fundamental noise measurements

f. Electron beam parametric amplifiers

g. Low-noise klystrons _._.

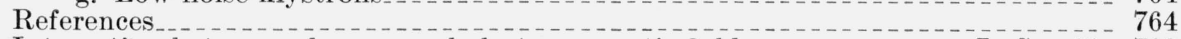

5. Interaction between plasmas and electromagnetic fields

5.1. Introduction

5.2. Propagation of electromagnetic waves in unbounded plasmas-small signal theory _...

5.3. Plasma waveguides

5.4. Electron stimulated plasma oscillations

5.5. Large signal oscillations

References _._.

Publications of the staff of the National Bureau of Standards $\ldots \ldots \ldots 9$

Index to volume 64D. Radio Propagation, Jan.-Dec. 1960 773

\section{Figures}

Commission 2, Tropospheric Radio Propagation

Figure 1. Attenuation due at one atmosphere

Figure 2. Water vapor attenuation for $7.5 \mathrm{~g} / \mathrm{cm}_{\ldots} \ldots 11$

Figure 3. Beyond horizon transmission

Figure 4. Theoretical smooth earth curves

Commission 6, Radio Waves and Circuits

Subcommission 6.2, Circuit Theory

Figure 1. Chain of five 1-ohm resistances realizing the given impedance matrix _._ 692

Figure 2. Idealized parametric amplifier

Figure 3. Possible form for realization of any active transfer function

Figure 4. Representation of an active driving-point function

Figure 5. Signal-flow diagram of the classical method of active RC network design.- 700

Figure 6. Network realizing the given RC voltage ratio (values in ohms and farads) _. 702 